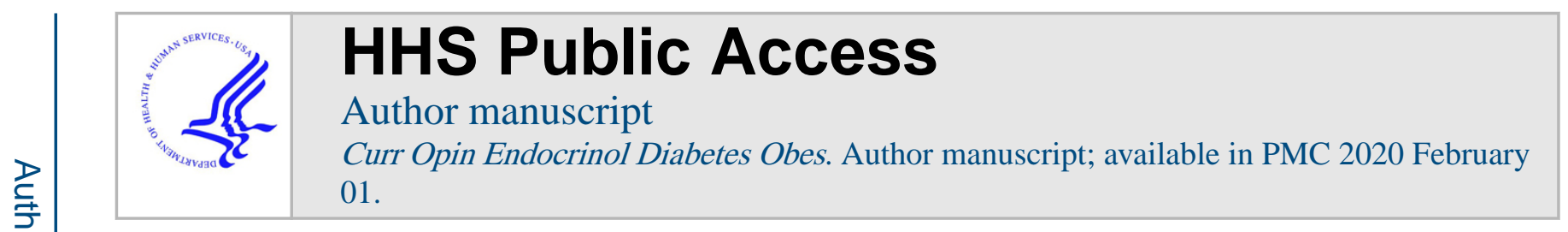

Published in final edited form as:

Curr Opin Endocrinol Diabetes Obes. 2019 February ; 26(1): 11-16. doi:10.1097/MED. 0000000000000449.

\title{
Central control of gastrointestinal motility
}

\author{
Kirsteen N. Browning and R. Alberto Travagli \\ Department of Neural and Behavioral Science, Penn State College of Medicine, Hershey, \\ Pennsylvania, USA
}

\begin{abstract}
Purpose of review-This review summarizes the organization and structure of vagal neurocircuits controlling the upper gastrointestinal tract, and more recent studies investigating their role in the regulation of gastric motility under physiological, as well as pathophysiological, conditions.
\end{abstract}

Recent findings - Vagal neurocircuits regulating gastric functions are highly plastic, and open to modulation by a variety of inputs, both peripheral and central. Recent research in the fields of obesity, development, stress, and neurological disorders highlight the importance of central inputs onto these brainstem neurocircuits in the regulation of gastric motility.

Summary-Recognition of the pivotal role that the central nervous system exerts in the regulation, integration, and modulation of gastric motility should serve to encourage research into central mechanisms regulating peripheral motility disorders.

\section{Keywords}

brainstem; gastrointestinal motility; neurodegenerative disorders; obesity; stress; vagus

\section{INTRODUCTION}

Langley [1] described the enteric nervous system (ENS) as a third branch of the autonomic nervous system confirming that the stomach and gastrointestinal tract can function largely independently from central nervous system (CNS) control. Although the ENS is certainly a highly complex neural network that endows the gastrointestinal tract with sophisticated reflexes and elaborate intrinsic control, it is also clear that the extrinsic innervation to the gastrointestinal tract, arising from both the sympathetic and parasympathetic branches of the autonomic nervous system, provides important integration, regulation, modulation, and coordination of gastrointestinal functions. This review will describe the basic neuro-circuitry of extrinsic, principally parasympathetic, inputs to the gastrointestinal tract, as well as the role of the CNS in regulation of the physiology and pathophysiology of gastrointestinal motility.

Correspondence to Kirsteen N. Browning, PhD, Department of Neural and Behavioral Science, Penn State College of Medicine, 500 University Drive, MC H109, Hershey, PA 17033, USA. Tel: +1 717531 8267; kbrowning@ pennstatehealth.psu.edu.

Conflicts of interest

There are no conflicts of interest. 


\section{SYMPATHETIC CONTROL OF THE GASTROINTESTINAL TRACT}

Sympathetic innervation to the gastrointestinal tract arise from the intermediolateral column of the thoracolumbar spinal cord [2] and provide a principally inhibitory input to gastrointestinal smooth muscle, a tonic inhibitory influence over mucosal secretion, and regulation of blood flow throughout the gastrointestinal tract, via neurally dependent vasoconstriction. Sympathetic inputs can modulate motility mostly via indirect, presynaptic modulation of neurotransmitter release; sympathetic regulation of motility, however, appears limited, at least when compared to the extensive control exerted by the parasympathetic nervous system.

\section{PARASYMPATHETIC CONTROL OF THE GASTROINTESTINAL TRACT}

In contrast to the somewhat unimodal control exerted by the sympathetic nervous system, the parasympathetic nervous system provides both excitatory and inhibitory inputs to the stomach and small intestine allowing for more precise, responsive, and discriminating control over gastrointestinal functions. Extrinsic parasympathetic inputs to the stomach and upper gastrointestinal tract are provided by the vagus (Xth cranial) nerve, the efferent (motor) cell bodies of which are located within the dorsal motor nucleus of the vagus (DMV) within the hindbrain. The efferent projections of these motoneurons form distinct vagal branches which have discrete subdiaphragmatic innervation patterns [3-5] and DMV neurons can be subdivided into distinct subgroups, based upon their morphological, biophysical, and functional properties as well as their visceral target organ [6].

Several studies, both in vivo and in vitro, have shown that DMV neurons regulating gastric functions are tonically active and exhibit 'pacemaker' properties, firing action potentials at a regular rate of around $1 \mathrm{~Hz}[7,8]$. In part, this is due the intrinsic biophysical properties of these neurons, but DMV neuronal activity is also controlled to a large degree by tonically active synaptic inputs, particularly from the adjacent nucleus tractus solitarius (NTS). Both in-vivo and in-vitro neurophysiological studies have shown that although DMV neurons also receive catecholaminergic and excitatory glutamatergic inputs, under basal conditions, it is the ongoing, tonic gamma amino butyric acid (GABAergic) inhibitory synaptic input that plays the most significant role in regulating DMV neuronal activity [8-11]. Modulation of these critically important GABAergic synaptic inputs, therefore, has the potential to exert profound effects upon DMV neuronal excitability, and vagal efferent control of gastric motility. NTS neurons are themselves the recipient of afferent (sensory) vagal inputs from thoracic and subdiaphragmatic organs $[12,13]$. Together with the area postrema, the NTS and DMV collectively form the dorsal vagal complex (DVC), the locus for central control of gastric functions, including motility.

\section{PHYSIOLOGY AND PATHOPHYSIOLOGY OF CENTRAL MODULATION OF GASTRIC FUNCTIONS}

It is well recognized that gastrointestinal neurohormones, released from enteroendocrine cells lining the gastrointestinal tract, exert paracrine actions on peripheral vagal afferent terminals to modulate vagally dependent gastric functions. Cholecystokinin (CCK), 
serotonin, and glucagon-like peptide 1 (GLP-1) released from enteroendocrine cells following ingestion of nutrients activate vagal afferent terminals [14-16]; the resulting excitatory signal is relayed centrally, activates NTS neurons, and induces reflexive gastric relaxation via either activation of the inhibitory non adrenergic non cholinergic pathway or inhibition and withdrawal of the tonically active cholinergic pathway [17]. Perhaps less well appreciated, but no less important, are the direct actions on central vagal neurocircuits that these circulating neuropeptides may also exert. As a circumventricular organ lying ventral to the fourth ventricle, the DVC is surrounded by fenestrated capillaries, Virchow-Robin perivascular spaces, and a loose blood brain barrier, allowing circulating neurohormones, neuropeptides, and neuromodulators much greater access to act directly on central vagal neurocircuits to alter their activity $[18,19]$. Indeed, peripheral CCK has been shown to activate vagal neurocircuits directly, even in the absence of vagal afferents [20].

Interestingly, the many of the same neuropeptides that activate peripheral vagal afferent terminals are also expressed by neurons within central vagal neurocircuits. For example, preproglucagon-immunoreactive (i.e., GLP-1 containing) neurons are located within the NTS and medullary reticular formation, and provide an extensive central network through which GLP-1 receptor signaling reduces food intake and modulates autonomic responsiveness [21]. It remains to be clarified, however, whether the central neurons modulated by circulating neurohormones directly are the same as those ones activated synaptically following paracrine actions of the same neurohormones at peripheral vagal afferent terminals. Notably, recent studies have demonstrated that preproglucagon-immunoreactive neurons do not express GLP-1 receptor-immunoreactive and do not respond directly to GLP-1 suggesting a potential disconnect between the neuropathways engaged by GLP-1 at the peripheral (vagal afferent) and central (NTS) levels [22]. It remains to be determined whether such an apparent disconnect is common to other central peptidergic systems within the CNS in general, or within central vagal neurocircuitry in particular.

Somewhat surprisingly, given the importance of GABAergic NTS-DMV synaptic transmission in regulating vagal efferent outflow to the stomach, this synapse is remarkably resistant to modulation, at least under basal in-vivo and in-vitro conditions. Work from our own laboratories have shown that the 'state of activation' of this critical inhibitory NTSDMV synapse is determined by ongoing vagal afferent activity [23,24]. Vagal afferents make monosynaptic connections with inhibitory NTS terminals [25]; the tonic release of glutamate from vagal afferent terminals activates presynaptic group II metabotropic glutamate receptors, which are negatively coupled to adenylate cyclase. By reducing cAMP levels, hence PKA activation, many neurotransmitters/ modulators (e.g., serotonin [26], $\mu$ opioid receptors [27,28], neuropeptide Y and peptide YY [29], oxytocin [30], and insulin [31]) are thus unable to regulate GABAergic synaptic transmission. Removal of this tonic metabotropic glutamate receptor activation, however, either by decreasing vagal afferent input, by blocking metabotropic glutamate receptors, or by activating adenylate cyclase directly, disinhibits the activity of these inhibitory terminals, allowing such previously resistant synapses to be modulated [32].

This becomes of physiological importance when one considers the myriad of potential endogenous activators of adenylate cyclase within these neurocircuits, including feeding 
neuropeptides like CCK and GLP-1, stress hormones such as corticotrophin releasing factor (CRF), endocrine hormones such as insulin, and - importantly - even vagal afferent activity itself. The degree of tonic synaptic inhibition of DMV neurons, and therefore vagal efferent activity to the upper gastrointestinal tract, appears to be remarkably labile and exquisitely responsive to ongoing physiological conditions. Indeed, a series of recent elegant studies have shown that, in rodents, the mechanosensitivity of vagal afferents, that is, their ability to respond to gastric stretch and distention hence appropriately regulate food intake and satiation, is subject to diurnal rhythms. The sensitivity of gastric vagal afferents is lowest during the dark cycle, for example, and is associated with increased food intake in line with energy demand [33]. Exposure to a high-fat diet (HFD) ablates this circadian rhythmicity resulting in increased food intake during the light cycle, contributing to the development of obesity [34"']. Time-restricted feeding, however, prevented the HFD-induced loss of circadian rhythmicity suggesting that vagal afferent sensitivity may be entrained not only by nutrient content, but by the timing of food intake [35"]. The capacity of time-restricted feeding regimens to prevent diet-induced loss of normal vagal circadian rhythmicity, and potentially restore appropriate vagal afferent and efferent functions, has potential important implications for the therapeutic treatment of obesity.

\section{DIET-INDUCED MODULATION OF CENTRAL VAGAL NEUROCIRCUITS}

The regulation of food intake and satiety is complex, involving both homeostatic and hedonic components [36-38]. Although the influence of vagal neurocircuits on the homeostatic regulation of feeding behavior is well recognized, less attention has been paid to the effects that HFD and DIO exert directly on gastric-projecting DMV neurons. Following HFD or DIO, DMV neurons are less excitable and less responsive to satiety neuropeptides $[39,40]$, hence vagal efferent control of the upper gastrointestinal tract is reduced. Indeed, obesity is associated with dysregulated gastric motility, altered gastric emptying rates, and an increase in gastric volume, which appears to delay satiation by requiring a larger volume of food to be ingested before signaling fullness [41-43].

Even acute periods of HFD exposure (3-5 days) alter vagal neurocircuitry, however. Upon initial exposure to a HFD, caloric intake increases; within 3-5 days, however, homeostatic regulation reduces food intake to restore caloric balance. Recent studies have shown that this period of autonomic regulation is associated with, and potentially determined by, plasticity within central vagal neurocircuits. Under basal conditions, glutamatergic NTS-DMV synaptic transmission is mediated via a-amino-3-hydroxy-5-methyl-4-isoxazolepropionic acid-receptor signaling; following acute HFD exposure, however, excitatory NTS-DMV glutamatergic transmission is increased via the recruitment and activation of synaptic Nmethyl-D-aspartate receptors which plays a significant role in determining DMV neuron excitability, preserving vagal efferent activity to the stomach, and the retention of appropriate gastric functions, including motility [44"']. Such rapid alterations in the central regulation of gastric functions provide further support for the concept for the homeostatic regulation of vagal neurocircuitry to maintain appropriate central control of gastric functions in the face of altered physiological demand or conditions. 


\section{EARLY LIFE EVENTS AND DEVELOPMENTAL MODULATION OF CENTRAL VAGAL NEUROCIRCUITS}

As a general principle, during critical periods of neurodevelopment, the brain undergoes considerable synaptic plasticity, pruning, and circuit refinement, during which temporally regulated neurocircuit maturation and patterning occurs. Disruption to these critical developmental periods, either genetic, epigenetic, or environmental, may result in impaired neurocircuit 'hard-wiring' and altered output responses. From the standpoint of central control of gastroin-testinal functions, descending preautonomic inputs from the hypothalamus, central nucleus of the amygdala, bed nucleus of the stria terminalis, and cortex reach the DVC in the first postnatal week and continue to mature into the second postnatal week [45-47]. Early life experience, therefore, has the potential to modulate neurocircuit development hence exert profound effects upon the predisposition to develop functional gastrointestinal disorders, including affecting visceral sensory responsiveness, and decreasing stress resilience and/or increasing stress susceptibility [48,49]

In rodent models, early life adverse events have been shown to modify the developmental assembly and maturation of autonomic homeostatic neurocircuits, including those within the hypothalamus and brainstem that regulate gastrointestinal functions. Repeated brief maternal separation during the early neonatal period, for example, decreases stress reactivity in adults, whereas more stressful early life events, such as prolonged maternal separation or neonatal limited nesting, increases stress reactivity and visceral hypersensitivity in adulthood. Such developmental manipulations were associated with a delay in the assembly of central visceral neurocircuits, particularly in the establishment and synaptic connectivity of descending 'preautonomic' inputs [50,51]. Maternal diet can also exerts profound effects upon neurodevelopment [52]; exposure to a maternal HFD, for example, increases the inhibition of gastric-projecting DMV neurons, decreasing their excitability, possibly contributing to the dysregulated vagal control of gastric functions. [53], and also increases stress reactivity in adulthood [52,54].

\section{STRESS AND MODULATION OF GASTRIC FUNCTIONS}

Stress may be considered as a state of threatened homeostatic imbalance, caused either by intrinsic or extrinsic factors, that is counteracted by an array of autonomic and behavioral responses designed to reestablish equilibrium. Stress itself is neither deleterious nor harmful; rather, it is the inability to cope effectively with stress that is injurious and detrimental to health. Brief stressors may even be considered protective, allowing transient adaptation to internal or external threats, whereas prolonged stress represents a more serious challenge to ongoing homeostasis, requiring a more sustained engagement of both autonomic and behavioral neurocircuits to restore function. The lack of appropriate adaptation to prolonged stress can exert profound effects upon gastrointestinal functions, decreasing gastric emptying and increasing colonic motility [55-59]. In susceptible individuals, however, functional gastrointestinal disorders are correlated highly with stress, and stress aggravates and worsens gastrointestinal functions [60-62]. Although stress engages the hypothalamic-pituitaryadrenal axis to produce a concerted endocrine response, it also activates the brain-gut axis, 
and engages descending CRF, oxytocinergic, and catecholaminergic inputs which regulate and modulate vagal efferent projections to the gastrointestinal tract $[61,63,64]$. Indeed, recent several studies in rodents have shown that stress adaptability is associated with an upregulation of oxytocin and catecholaminergic inputs to the DVC $[65,66]$ which are essential for the restoration of gastrointestinal functions.

\section{NEUROLOGICAL DISEASES AND CONTROL OF GASTROINTESTINAL FUNCTIONS}

The dysregulation and dysfunction of gastrointestinal functions that occurs in response to neurological diseases has justifiably been the subject of increased attention from several laboratories. Gastrointestinal dysregulation is commonly associated with multiple sclerosis [67,68], autism [69,70], schizophrenia [71], and Parkinson's disease [72,73], to name but a few CNS disorders, because of both central and peripheral dysfunction.

The gastrointestinal dysfunction in Parkinson's Disease has, perhaps, received the most concerted attention recently, although, having been described by James Parkinson in his original treatise on the disease, the involvement of the gastrointestinal tract in Parkinson's Disease is hardly novel. Dysphagia, sialorrhea, gastroparesis, and constipation affect a significant proportion of Parkinson's Disease patients; indeed, gastrointestinal dysfunctions are frequently prodromal to the well described motor symptoms, often occurring even decades before official diagnosis [74]. Recently, however, the description of a novel nigrovagal neuropathway has demonstrated that a direct, monosynaptic connection exists between the substantia nigra pars compacta ( $\mathrm{SNpc}$ ) and the DVC, including neurons of the DMV, and exerts a tonic influence over gastric motility and tone. Optogenetic inhibition of these nigrovagal nerve terminals within the DVC inhibits basal gastric tone and motility, and attenuates the increased motility and tone induced by stimulation of the SNpc [75'- $]$. The finding of a direct descending connection between the SNpc and the DVC also provides strong support for the hypothesis first put forward by Braak et al. [76-78] that idiopathic Parkinson's Disease may result from ingestion of an environmental toxin which induces a distinct sequence of pathological and degenerative events, affecting the ENS first before traveling centrally in a retrograde fashion via the efferent vagus nerve to affect neurons of the DMV, and from thence ascending to affect the SNpc, via this newly described nigro-vagal pathway [75"']. More broadly speaking, however, the extensive connectivity of the DVC and its central role in the integration of ascending (interoceptive) inputs and descending (motor) outputs suggests a means by which gastro-intestinal dysfunctions associated with other neurological disorders may be explained, investigated, and understood.

\section{CONCLUSION}

Although the central control of gastrointestinal functions, particularly vagal (parasympathetic) control of motility, is understood at a basic neurocircuit level, there is still much work to be done to understand the many and varied means by which the CNS is involved in gastrointestinal physiology, and pathophysiology. Work from several laboratories in recent years has highlighted not only the remarkable degree of plasticity within vagal neurocircuits controlling gastrointestinal motility, but also the importance of inputs from 
other brainstem, midbrain, and higher cortical centers in the regulation of vagal neuronal activity and efferent output. It is unsurprising, therefore, that gastrointestinal motility disturbances are common, often chronic and disabling, conditions. Increasing awareness of the pivotal role that the CNS plays in the gastrointestinal physiology and pathophysiology should serve to encourage and facilitate research into 'big brain' aspects of 'little brain' problems.

\section{Acknowledgements}

We thank W. Nairn Browning as well as Cesare M. and Zoraide Travagli for their support and encouragement.

Financial support and sponsorship

This work was supported by NIH grants DK 78364 (KNB), DK 55530, and DK 99350 (AT).

\section{REFERENCES AND RECOMMENDED READING}

Papers of particular interest, published within the annual period of review, have been highlighted as:

- of special interest

- of outstanding interest

1. Langley JN. The autonomic nervous system, part 1. Cambridge: W. Heffer \& Sons Ltd; 1921.

2. Furness JB. The enteric nervous system and neurogastroenterology. Nat Rev Gastroenterol Hepatol 2012; 9:286-294. [PubMed: 22392290]

3. Fox EA, Powley TL. Longitudinal columnarorganization withinthedorsal motor nucleus represents separate branches of the abdominal vagus. Brain Res 1985; 341:269-282. [PubMed: 4041795]

4. Norgren R, Smith GP. Central distribution of subdiaphragmatic vagal branches in the rat. J Comp Neurol 1988; 273:207-223. [PubMed: 3417902]

5. Shapiro RE, Miselis RR. The central organization ofthe vagus nerve innervating the stomach ofthe rat. J Comp Neurol 1985; 238:473-488. [PubMed: 3840183]

6. Browning KN, Renehan WE, Travagli RA. Electrophysiological and morphological heterogeneity of rat dorsal vagal neurones which project to specific areas of the gastrointestinal tract. J Physiol 1999; 517:521-532. [PubMed: 10332099]

7. Travagli RA, Gillis RA. Hyperpolarization-activated currents IH and IKIR in rat dorsal motor nucleus of the vagus neurons, in vitro. J Neurophysiol 1994; 71:1308-1317. [PubMed: 8035216]

8. Travagli RA, Gillis RA, Rossiter CD, Vicini S. Glutamate and GABA-mediated synaptic currents in neurons ofthe ratdorsal motor nucleus ofthevagus. AmJ Physiol 1991; 260:G531-G536. [PubMed: 1672243]

9. Sivarao DV, Krowicki ZK, Hornby PJ. Role of GABAA receptors in rat hindbrain nuclei controlling gastric motor function. Neurogastroenterol Motil 1998; 10:305-313. [PubMed: 9697105]

10. Davis SF, Derbenev AV, Williams KW, et al. Excitatory and inhibitory local circuit input to the rat dorsal motor nucleus of the vagus originating from the nucleus tractus solitarius. Brain Res 2004; 1017:208-217. [PubMed: 15261116]

11. Babic T, Browning KN, Travagli RA. Differential organization of excitatory and inhibitory synapses within the rat dorsal vagal complex. Am J Physiol Gastro-intest Liver Physiol 2011; 300:G21-G32.

12. Altschuler SM, Bao X, Bieger D, et al. Viscerotopic representation of the upper alimentarytract in the rat: sensory ganglia and nuclei ofthe solitary and spinal trigeminal tracts. J Comp Neurol 1989; 283:248-268. [PubMed: 2738198]

13. Broussard DL, Altschuler SM. Brainstem viscerotopic organization of afferents and efferents involved in the control of swallowing. Am J Med 2000; 108:79S-86S. [PubMed: 10718457] 
14. Raybould HE. Does your guttaste? Sensory transduction in the gastrointestinal tract. News Physiol Sci 1998; 13:275-280. [PubMed: 11390803]

15. Raybould HE. Visceral perception: sensory transduction in visceral afferents and nutrients. Gut 2002; 51(Suppl 1):I11-I14. [PubMed: 12077056]

16. Dockray G Gutendocrine secretions and their relevancetosatiety. CurrOpin Pharmacol 2004; 4:557-560.

17. Browning KN, Travagli RA. Central nervous system control of gastrointestinal motility and secretion and modulation of gastrointestinal functions. Compr Physiol 2014; 4:1339-1368. [PubMed: 25428846]

18. Cottrell GT, Ferguson AV. Sensory circumventricular organs: central roles in integrated autonomic regulation. Regul Pept 2004; 117:11-23. [PubMed: 14687696]

19. Fry M, Ferguson AV. The sensory circumventricular organs: brain targets for circulating signals controlling ingestive behavior. Physiol Behav 2007; 91:413-423. [PubMed: 17531276]

20. Baptista V, Browning KN, Travagli RA. Effects of cholecystokinin-8s in the nucleus tractus solitarius of vagally deafferented rats. Am J Physiol Regul Integr Comp Physiol 2007; 292:R1092R1100. [PubMed: 17122331]

21. Trapp S, Richards JE. The gut hormone glucagon-like peptide-1 produced in brain: is this physiologically relevant? Curr Opin Pharmacol 2013; 13: 964-969. [PubMed: 24075717]

22. Card JP, Johnson AL, Llewellyn-Smith IJ, et al. Glp-1 neurons form a local synaptic circuit within the rodent nucleus ofthe solitary tract. J Comp Neurol 2018; 526:2149-2164. [PubMed: 30019398]

23. Browning KN, Travagli RA. Plasticity of vagal brainstem circuits in the control of gastrointestinal function. Auton Neurosci 2011; 161:6-13. [PubMed: 21147043]

24. Browning KN, Travagli RA. Plasticity of vagal brainstem circuits in the control of gastric function. Neurogastroenterol Motil 2010; 22:1154-1163. [PubMed: 20804520]

25. Rinaman L, Card JP, Schwaber JS, Miselis RR. Ultrastructural demonstration ofagastric monsynaptic vagal circuit in the nucleus ofthe solitarytract in rat. J Neurosci 1989; 9:1985-1996. [PubMed: 2723763]

26. Browning KN, Travagli RA. The peptide TRH uncovers the presence of presynaptic 5-HT1A receptors via activation of a second messenger pathway in the rat dorsal vagal complex. J Physiol 2001; 531:425-435. [PubMed: 11230515]

27. Browning KN, Kalyuzhny AE, Travagli RA. Mu-opioid receptor trafficking on inhibitory synapses in the rat brainstem. J Neurosci 2004; 24:7344-7352. [PubMed: 15317860]

28. Browning KN, Kalyuzhny AE, Travagli RA. Opioid peptides inhibit excitatory but not inhibitory synaptic transmission in the rat dorsal motor nucleus ofthe vagus. J Neurosci 2002; 22:2998-3004. [PubMed: 11943802]

29. Browning KN, Travagli RA. Modulation of inhibitory neurotransmission in brainstem vagal circuits by NPY and PYY is controlled by camp levels. Neurogastroenterol Motil 2009; 21:13091318. [PubMed: 19622099]

30. Browning KN, Babic T, Toti L, et al. Plasticity in the brainstem vagal circuits controlling gastric motorfunction triggered by corticotropin releasing factor. J Physiol 2014; 592:4591-4605. [PubMed: 25128570]

31. Blake CB, Smith BN. Camp-dependent insulin modulation of synaptic inhibition in neurons of the dorsal motor nucleus of the vagus is altered in diabetic mice. Am J Physiol Regul Integr Comp Physiol 2014; 307:R711-R720. [PubMed: 24990858]

32. Browning KN, Travagli RA. Functional organization of presynaptic metabotropic glutamate receptors in vagal brainstem circuits. J Neurosci 2007; 27:8979-8988. [PubMed: 17715335]

33. Kentish SJ, Frisby CL, Kennaway DJ, et al. Circadian variation in gastric vagal afferent mechanosensitivity. J Neurosci 2013; 33:19238-19242. [PubMed: 24305819]

34m. Kentish SJ,Vincent AD, Kennaway DJ, et al. High-fatdiet-induced obesity ablates gastric vagal afferent circadian rhythms. J Neurosci 2016; 36:3199-3207.

This manuscript defines the circadian rhythmicity of gastric mechanosensitive vagal afferents, which renders vagal mechanosensors less sensitive to gastric stretch and distention during the dark period, allowing increased food intake at a time of higher energy demand. HFD ablates this 
normal diurnal rhythm, decreasing mechanosensitivity during the light period, increasing food intake, and contributing to the development of obesity

. [PubMed: 26985030]

35-. Kentish SJ, Hatzinikolas G, Li H, et al. Time-restricted feeding prevents ablation ofdiurnal rhythms in gastric vagal afferent mechanosensitivity observed in high-fat diet-induced obese mice. J Neurosci 2018; 38:5088-5095.

This manuscript describes the effects of time-restricted feeding to prevent the actions of HFD to ablate diurnal rhythmicity in gastric mechanosensitive vagal afferents, implying that vagal afferent function can be modulated by both nutrient content as well as timing of food intake

. [PubMed: 29760179]

36. Berthoud HR. Homeostatic and nonhomeostatic pathways involved in the control of food intake and energy balance. Obesity (Silver Spring) 2006; 14(Suppl 5):197S-200S. [PubMed: 17021366]

37. Berthoud HR, Morrison C. The brain, appetite, and obesity. Annu Rev Psychol 2008; 59:55-92. [PubMed: 18154499]

38. Schwartz MW, Woods SC, Porte D, et al. Central nervous system control of food intake. Nature 2000; 404:661-671. [PubMed: 10766253]

39. Bhagat R, Fortna SR, Browning KN. Exposure to a high fat diet during the perinatal period alters vagal motoneurone excitability, even in the absence of obesity. J Physiol 2015; 593:285-303. [PubMed: 25556801]

40. Browning KN, Fortna SR, Hajnal A. Roux-en-Y gastric bypass reverses the effects of diet-induced obesity to inhibit the responsiveness of central vagal motoneurones. J Physiol 2013; 591:23572372. [PubMed: 23459752]

41. Camilleri M Peripheral mechanisms in appetite regulation. Gastroenterology 2015; 148:12191233. [PubMed: 25241326]

42. Feinle-Bisset C Upper gastrointestinal sensitivity to meal-related signals in adult humans: relevance to appetite regulation and gut symptoms in health, obesity and functional dyspepsia. Physiol Behav 2016; 162:69-82. [PubMed: 27013098]

43. Janssen P, Vanden Berghe P, Verschueren S, et al. Review article: the role of gastric motility in the control of food intake. Aliment Pharmacol Ther 2011; 33:880-894. [PubMed: 21342212]

44-. Clyburn C, Travagli RA, Browning KN. Acute high-fat diet upregulates glutamatergic signaling in the dorsal motor nucleus ofthe vagus. Am J Physiol Gastrointest Liver Physiol 2018; 314:G623-G634.

This study describes diet-induced short-term plasticity in central vagal neurocircuits that regulates vagal efferent control of gastric functions and may be of importance in the homeostatic regulation of food intake and caloric consumption

. [PubMed: 29368945]

45. Rinaman L Postnatal development of central feeding circuits In: Stricker E, Woods S, editors. Neurobiology of food and fluid intake, vol. 14 New York: Plenum Publishers; 2004 pp. 159-194.

46. Rinaman L Postnatal development of hypothalamic inputs to the dorsal vagal complex in rats. Physiol Behav 2003; 79:65-70. [PubMed: 12818710]

47. Rinaman L, Levitt P. Establishment of vagal sensorimotor circuits during fetal development in rats. J Neurobiol 1993; 24:641-659. [PubMed: 7686963]

48. Rinaman L, Banihashemi L, Koehnle TJ. Early life experience shapes the functional organization of stress-responsive visceral circuits. Physiol Behav 2011; 104:632-640. [PubMed: 21497616]

49. Greenwood-Van Meerveld B, Johnson AC. Stress-induced chronic visceral pain of gastrointestinal origin. Front Syst Neurosci 2017; 11:86. [PubMed: 29213232]

50. Banihashemi L, Rinaman L. Repeated brief postnatal maternal separation enhances hypothalamic gastric autonomic circuits in juvenile rats. Neuroscience 2010; 165:265-277. [PubMed: 19800939] 
51. Card JP, Levitt P, Gluhovsky M, Rinaman L. Early experience modifies the postnatal assembly of autonomic emotional motor circuits in rats. J Neurosci 2005; 25:9102-9111. [PubMed: 16207869]

52. Sasaki A, de Vega WC, St-Cyr S, et al. Perinatal high fat diet alters glucocorticoid signaling and anxiety behavior in adulthood. Neuroscience 2013; 240:1-12. [PubMed: 23454542]

53. McMenamin CA, Travagli RA, Browning KN. Perinatal high fat diet increases inhibition of dorsal motor nucleus of the vagus neurons regulating gastric functions. Neurogastroenterol Motil 2017; 30:. doi: 10.1111/nmo.13150.

54. Sullivan EL, Smith MS, Grove KL. Perinatal exposure to high-fatdiet programs energy balance, metabolism and behavior in adulthood. Neuroendocrinology 2011; 93:1-8. [PubMed: 21079387]

55. Babygirija R, Zheng J, Ludwig K, Takahashi T. Central oxytocin is involved in restoring impaired gastric motility following chronic repeated stress in mice. Am J Physiol Regul Integr Comp Physiol 2010; 298:R157-R165. [PubMed: 19889866]

56. Bulbul M, Babygirija R, Ludwig K, Takahashi T. Central oxytocin attenuates augmented gastric postprandial motility induced by restraint stress in rats. Neurosci Lett 2010; 479:302-306. [PubMed: 20639005]

57. Nakade Y, Tsuchida D, Fukuda H, et al. Restraint stress delays solid gastric emptying via a central corticotropin-releasing factor and peripheral sympathetic neuron in rats. Am J Physiol Regul Integr Comp Physiol 2005; 288:R427-R432. [PubMed: 15458973]

58. Tsukamoto K, Nakade Y, Mantyh C, et al. Peripherally administered CRF stimulates colonic motility via central CRF receptors and vagal pathways in conscious rats. Am J Physiol Regul Integr Comp Physiol 2006; 290:R1537-R1541. [PubMed: 16284082]

59. Zheng J, Dobner A, Babygirija R, et al. Effects of repeated restraint stress on gastric motility in rats. Am J Physiol Regul Integr Comp Physiol 2009; 296:R1358-R1365. [PubMed: 19261914]

60. Stengel A, Tache Y. Neuroendocrine control of the gut during stress: corticotropin-releasing factor signaling pathways in the spotlight. Annu Rev Physiol 2009; 71:219-239. [PubMed: 18928406]

61. Tache Y, Bonaz B. Corticotropin-releasing factor receptors and stress-related alterations of gut motor function. J Clin Invest 2007; 117:33-40. [PubMed: 17200704]

62. Khoo J, Rayner CK, Feinle-Bisset C, et al. Gastrointestinal hormonal dysfunction in gastroparesis and functional dyspepsia. Neurogastroenterol Motil 2010; 22:1270-1278. [PubMed: 20939851]

63. Czimmer J, Tache Y. Peripheral corticotropin releasing factorsignaling inhibits gastric emptying: mechanisms of action and role in stress-related gastric alterations of motor function. Curr Pharm Des 2017; 23:4042-4047. [PubMed: 28245760]

64. Babygirija R, Bulbul M, Yoshimoto S, et al. Central and peripheral release of oxytocin following chronic homotypic stress in rats. Auton Neurosci 2012; 167:56-60. [PubMed: 22245139]

65. Jiang Y, Browning KN, Toti L, Travagli RA. Vagally mediated gastric effects of brain stem a 2 adrenoceptor activation in stressed rats. Am J Physiol Gastrointest Liver Physiol 2018; 314:G504G516. [PubMed: 29351390]

66. Jiang Y, Holly Coleman F, Kopenhaver Doheny K, Alberto Travagli R. Stress adaptation upregulates oxytocin within hypothalamo-vagal neurocircuits. Neuroscience 2018; 390:198-205. [PubMed: 30176320]

67. Spear ET, Holt EA, Joyce EJ, et al. Altered gastrointestinal motility involving autoantibodies in the experimental autoimmune encephalomyelitis model of multiple sclerosis. Neurogastroenterol Motil 2018; 30:e13349. [PubMed: 29644797]

68. Wunsch M, Jabari S, Voussen B, et al. The enteric nervous system is a potential autoimmune target in multiple sclerosis. Acta Neuropathol 2017; 134:281-295. [PubMed: 28620692]

69. Israelyan N, Margolis KG. Serotonin as a link between the gut-brain-microbiome axis in autism spectrum disorders. Pharmacol Res 2018; 132:1-6. [PubMed: 29614380]

70. McElhanon BO, McCracken C, Karpen S, Sharp WG. Gastrointestinal symptoms in autism spectrum disorder: a meta-analysis. Pediatrics 2014; 133:872-883. [PubMed: 24777214]

71. Severance EG, Prandovszky E, Castiglione J, Yolken RH. Gastroenterology issues in schizophrenia: why the gut matters. Curr Psychiatry Rep 2015; 17:27. [PubMed: 25773227]

72. Pellegrini C, Colucci R, Antonioli L, et al. Intestinal dysfunction in Parkinson's disease: lessons learned from translational studies and experimental models. Neurogastroenterol Motil 2016; 28:1781-1791. [PubMed: 27611012] 
73. Travagli RA, Anselmi L. Vagal neurocircuitry and its influence on gastric motility. Nat Rev Gastroenterol Hepatol 2016; 13:389-401. [PubMed: 27251213]

74. Cersosimo MG, Benarroch EE. Neural control of the gastrointestinal tract: implications for Parkinson disease. Mov Disord 2008; 23: 1065-1075. [PubMed: 18442139]

75m. Anselmi L, Toti L, Bove C, et al. A nigro-vagal pathway controls gastric motility and is affected in a rat model of Parkinsonism. Gastroenterology 2017; 153:1581-1593.

This study describes a novel monosynaptic inputfromthe SNpc tothe dorsal vagal complex, which exerts a tonic modulatory role over gastric motility tone and is compromised in a rodent model of Parkisonism, providing further support to the hypothesis that idiopathic Parkinson's disease may spread from the gastrointestinal tract in a retrograde manner

. [PubMed: 28912019]

76. Braak H, Braak E. Pathoanatomy of Parkinson's disease. J Neurol 2000; 247(Suppl 2):113-10.

77. Braak H, Rub U, Gai WP, Del Tredici K. Idiopathic Parkinson's disease: possible routes by which vulnerable neuronal types may be subject to neuroinvasion by an unknown pathogen. J Neural Transm 2003; 110:517-536. [PubMed: 12721813]

78. Del Tredici K, Braak H. Review: sporadic Parkinson's disease: development and distribution of asynuclein pathology. Neuropathol Appl Neurobiol 2016; 42:33-50. [PubMed: 26662475] 


\section{KEY POINTS}

- The parasympathetic nervous system provides both excitatory and inhibitory inputs to the stomach and small intestine allowing for precise, responsive, and discriminating control over gastrointestinal functions.

- $\quad$ DMV neurons innervating the stomach are tonically active and provide a basal excitatory drive to the stomach via the efferent vagus nerve.

- Central vagal neurocircuits controlling gastrointestinal functions are remarkably plastic and open to modulation from other brainstem, midbrain, and higher cortical centers.

- The extensive connectivity of central vagal neurocircuits, and their prominent role in the integration of ascending (interoceptive) and descending (motor) outputs may provide a means by which gastrointestinal dysfunctions associated with neurological disorders can be explained. 